\title{
Fenologia de espécies lenhosas em um cerrado típico no Parque Municipal do Bacaba, Nova Xavantina, Mato Grosso, Brasil
}

\author{
Divino Vicente Silvério ${ }^{1,2}$ \& Eddie Lenza ${ }^{1}$

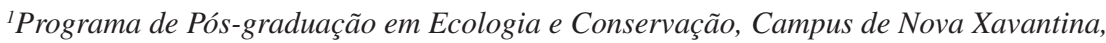 \\ Universidade do Estado de Mato Grosso - UNEMAT, BR 158, Km 148, CP 08, \\ CEP 78690-000, Nova Xavantina, MT, Brasil \\ ${ }^{2}$ Autor para correspondência: Divino Vicente Silvério, e-mail: vicentth@yahoo.com.br
}

SILVÉRIO, D.V. \& LENZA, E. Phenology of woody species in a typical cerrado in the Bacaba Municipal Park, Nova Xavantina, Mato Grosso, Brazil. Biota Neotrop. 10(3): http://www.biotaneotropica.org.br/v10n3/ en/abstract?article+bn03710032010.

\begin{abstract}
The goal of this study was to characterize the phenological behavior of 12 woody species, which together represent $41 \%$ of the Importance Value Index (IVI) of a typical cerrado (Brazilian savanna) in the Bacaba Municipal Park (Nova Xavantina, Mato Grosso), and to relate it to climatic variables, including precipitation, minimum temperatures, maximum temperatures and Vapor Pressure Deficit (VPD). Phenological observations were made every 15 days, from September 2008 to October 2009. Estimates were made of total leaf cover in the canopy, leaf flushing, relative proportion of young, adult, and senescent leaves and flowering and fruiting. Based on phenological vegetative events, four species were classified as evergreen with continuous growth (Myrcia lanuginosa O. Berg., Ouratea hexasperma (A. St.-Hil.) Baill., Ouratea spectabilis (Mart. ex Engl.) Engl. e Roupala montana Aubl.), one as evergreen with seasonal growth (Byrsonima pachyphylla Kunth), two as brevideciduous (Davilla elliptica A. St.-Hil., Eugenia aurata O. Berg.), and five as deciduous (Byrsonima coccolobifolia Kunth, Kielmeyera rubriflora Cambess., Qualea grandiflora Mart., Qualea multiflora Mart. and Qualea parviflora Mart.). All species showed an annual, unimodal flowering pattern, with different species flowering during distinct periods of the year. The fruit maturation of autochoric and anemochoric species occurred within the dry season mostly; zoochoric species dispersed seeds mainly during the wet season or during the transition between dry and rainy seasons. Leaf fall, estimated from leaf canopy cover, was negatively and significantly correlated to maximum temperature and vapor pressure deficit in 11 out of 12 species studied (except $R$. montana), suggesting that increasing temperature and evaporative demand induce foliar abscission. Leaf flushing was positively and significantly correlated to minimum temperature in nine species (except $M$. lanuginosa, $R$. montana and $Q$. grandiflora). Our results suggest that there is a strong relationship between the phenological events of the studied woody species and climatic conditions, with vegetative events like abscission and flushing showing the strongest associations.
\end{abstract}

Keywords: Cerrado, climate seasonality, leaffall, flowering, fruiting.

SILVÉRIO, D.V. \& LENZA, E. Fenologia de espécies lenhosas em um cerrado típico no Parque Municipal do Bacaba, Nova Xavantina, Mato Grosso, Brasil. Biota Neotrop. 10(3): http://www.biotaneotropica.org.br/ v10n3/pt/abstract?article+bn03710032010.

Resumo: O objetivo desse estudo foi caracterizar os comportamentos fenológicos de 12 espécies lenhosas, que juntas representam $41 \%$ do Valor de Importância (VI) de uma comunidade de cerrado típico no Parque Municipal do Bacaba, Nova Xavantina, MT, e relacioná-los à precipitação, temperaturas mínimas, máximas e Déficit de Pressão de Vapor (DPV). As observações fenológicas foram realizadas em intervalos quinzenais, de setembro 2008 a outubro de 2009. Foram estimadas as intensidades de cobertura total da folhagem na copa, brotamento, proporção relativa de folhas novas, adultas e senescentes, floração e frutificação. Baseado nos eventos fenológicos vegetativos, quatro espécies foram categorizadas como sempre-verde com crescimento contínuo (Myrcia lanuginosa O. Berg., Ouratea hexasperma (A. St.-Hil.) Baill., Ouratea spectabilis (Mart. ex Engl.) Engl. e Roupala montana Aubl.), uma como sempre-verde com crescimento sazonal (Byrsonima pachyphylla Kunth), duas como brevidecíduas (Davilla elliptica A. St.-Hil., Eugenia aurata O. Berg.) e cinco como decíduas (Byrsonima coccolobifolia Kunth, Kielmeyera rubriflora Cambess., Qualea grandiflora Mart., Qualea multiflora Mart. e Qualea parviflora Mart.). A floração de todas as espécies apresentou padrão anual e unimodal, com diferentes espécies florescendo em períodos distintos do ano. A maturação de frutos das espécies com dispersão zoocórica ocorreu principalmente durante o período chuvoso, e das com dispersão anemocórica ocorreu no período seco, ou na transição entre os períodos. A deciduidade foliar, estimada a partir da cobertura de folhagem, foi negativa e significativamente relacionada com temperatura máxima e com déficit de pressão de vapor em 11 das 12 espécies estudadas (exceto R. montana), sugerindo que aumentos na temperatura e na demanda evaporativa do ar induzem a abscisão foliar. O brotamento foi positivo e significativamente relacionado com a temperatura mínima em nove espécies (exceto $M$. lanuginosa, $R$. montana e $Q$. grandiflora). Os resultados permitem sugerir que há forte relação entre os eventos fenológicos das espécies lenhosas estudadas e as condições climáticas, com associações mais evidentes para os eventos vegetativos como abscisão e brotamento.

Palavras-chave: Cerrado, sazonalidade climática, deciduidade, floração, frutificação. 


\section{Introdução}

No bioma Cerrado, a precipitação ocorre predominantemente de outubro a abril, com certa restrição hídrica nos demais meses do ano (Silva et al. 2008). A redução pluviométrica diminui a disponibilidade de água para as plantas nas camadas superficiais do solo (Jackson et al. 1999, Franco 2002) e eleva a demanda evaporativa do ar (Bucci et al. 2005), levando em certos casos, à perda da folhagem das espécies arbóreas e a morte da parte aérea das espécies herbáceas e subarbustivas no período seco (Sarmiento \& Monasterio 1983, Filgueiras 2002, Bucci et al. 2005). A serapilheira produzida nesse período é uma importante fonte de nutrientes para as plantas, e consequentemente, para a ciclagem de nutrientes nesse sistema (Delitti 1995, Haridasan 2000), cujos solos são naturalmente oligotróficos (Haridasan 2000, Reatto et al. 2008). Por outro lado, a biomassa acumulada na serapilheira durante a estação seca serve como material combustível para a ocorrência de queimadas (Miranda et al. 2002, 2004), que promovem a mineralização e disponibilização imediata dos nutrientes para a vegetação (Frost \& Robertson 1987, Coutinho 1990, Miranda et al. 2004). Esta relação histórica entre sazonalidade climática, baixa fertilidade dos solos e ocorrência natural de queimadas, tem moldado nos últimos milhares de anos as diferentes estratégias vegetativas e reprodutivas das plantas do bioma Cerrado (Sarmiento \& Monasterio 1983, Bucci et al. 2005, Oliveira 2008, Miranda et al. 2004).

Espécies da flora lenhosa do Cerrado possuem estratégias variadas de alocação de recursos, para lidar com os fatores condicionantes descritos acima, durante as diversas fases do ciclo de vida (Oliveira \& Silva 1993, 2002, Marquis et al. 2002, Oliveira 2008). Entre estas, o comportamento fenológico parece ter se desenvolvido como uma resposta evolutiva à sazonalidade climática (Mantovani \& Martins 1988, Lenza \& Klink 2006, Oliveira 2008), à ocorrência do fogo (Felfili et al. 1999, Miranda et al. 2004), às atividades de polinizadores (Mantovani \& Martins 1988), dispersores (Oliveira 2008) e herbívoros (Marquis et al. 2002). Tais estratégias maximizam a reprodução e a sobrevivência das espécies (Oliveira 2008). Dessa forma, estudos sobre o comportamento fenológico possibilitam determinar as causas e consequências dos diversos fatores condicionantes sobre respostas funcionais das espécies, e permitem entender a regeneração e reprodução das espécies, a organização temporal dos recursos dentro das comunidades e as interações e coevolução entre plantas e animais (Lieth 1974, Talora \& Morellato 2000).

Em relação às fenofases vegetativas de plantas lenhosas de Cerrado, algumas espécies possuem adaptações para superar o estresse hídrico, como os xilopódios ou um sistema radicular bem desenvolvido (Eiten 1972, Jackson et al. 1999, Franco et al. 2005, Oliveira et al. 2005), permitindo-lhes produzir folhas durante o período seco e manter a folhagem ao longo do ano (Sarmiento et al. 1985, Franco et al. 2005, Lenza \& Klink 2006, Oliveira 2008). Em outro extremo, algumas espécies perdem completamente as folhas por um curto período de tempo durante a estação seca e, por isso, são categorizadas como brevidecíduas ou decíduas (Sarmiento et al. 1985, Franco et al. 2005, Lenza \& Klink 2006), minimizando a perda de água durante esta estação desfavorável. Essas variações no comportamento fenológico das espécies sugerem diferentes estratégias adaptativas aos mesmos fatores condicionantes (Lenza \& Klink 2006).

Em relação ao comportamento fenológico reprodutivo, o ajustamento da floração das espécies lenhosas do Cerrado é menos definido, havendo espécies em floração ao longo de todo ano (Mantovani \& Martins 1988, Batalha \& Mantovani 2000, Oliveira \& Gibbs 2000, Lenza \& Klink 2006). Fatores como precipitação, temperatura, fotoperíodo e ocorrência de fogo parecem induzir o início da floração (Fernandes-Bulhão \& Figueiredo 2002, Munhoz \& Felfili 2007, Oliveira 2008). Ademais, a disponibilidade ou competição por polinizadores, restrições filogenéticas ou período ótimo para dispersão também podem ser importantes para o ajustamento do período de floração (Fernandes-Bulhão \& Figueiredo 2002, Oliveira 2008). Assim, as espécies lenhosas de Cerrado podem apresentar diferentes períodos de floração, frutificação e dispersão das sementes, evidenciando estratégias distintas de ajustamento aos condicionantes bióticos e abióticos (Mantovani \& Martins 1988, Lenza \& Klink 2006, Munhoz \& Felfili 2007, Oliveira 2008).

Apesar do esforço empreendido nos últimos anos, os dados sobre o comportamento fenológico das espécies de Cerrado são, ainda, fragmentários (Oliveira 2008). Um número ainda muito reduzido de espécies tem seu comportamento fenológico descrito em detalhe (Lenza \& Klink 2006, Franco et al. 2005), considerando a elevada riqueza da flora lenhosa do Cerrado, com mais de 12 mil espécies (Mendonça et al. 2008). Além do mais, a maioria das espécies foi estudada em um único local, geralmente na área core do bioma, sendo desconhecidas possíveis variações geográficas no seu comportamento fenológico. Assim, considerando a grande extensão territorial e a heterogeneidade ambiental do Cerrado (Ratter et al. 2003, Bridgewater et al. 2004, Silva et al. 2006), tornase necessária a realização de mais estudos fenológicos que busquem melhor compreender as respostas funcionais das espécies nesses ambientes.

Este estudo teve por objetivo: 1) caracterizar o comportamento fenológico vegetativo e reprodutivo de 12 espécies lenhosas representativas, em termos de valor de importância, de um cerrado sentido restrito localizado no Parque Municipal do Bacaba, em Nova Xavantina, Mato Grosso; 2) identificar grupos fenológicos vegetativos para as espécies, levando em consideração aspectos temporais das distintas fenofases; e 3) relacionar o comportamento fenológico das espécies à precipitação total, médias quinzenais das temperaturas mínimas e máximas e déficit de pressão de vapor.

\section{Material e Métodos}

Este estudo foi realizado em um cerrado típico (ver Ribeiro \& Walter 2008) no Parque Municipal Mário Viana ou Parque Municipal do Bacaba em Nova Xavantina, MT. O Parque é uma unidade de conservação com 492 ha localizado às margens da BR 158, a uma altitude média de $340 \mathrm{~m}$, nas coordenadas de $14^{\circ} 41^{\prime} 09^{\prime \prime} \mathrm{S}$ e 52 20 ' 09" W, na porção Leste do Bioma Cerrado no Leste de Mato Grosso. A vegetação predominante é o cerrado sentido restrito, além de mata de galeria e manchas de cerradão e de cerrado rupestre. O clima da região é tipo Aw, de acordo com a classificação de Köppen, a temperatura média anual é $24^{\circ} \mathrm{C}$ e a precipitação em torno de $1.500 \mathrm{~mm}$ (Silva et al. 2008). Os solos da região são predominantemente distróficos, álicos, profundos, bem drenados e de textura média (Radambrasil 1981). Os solos da área de estudo apresentam $\mathrm{pH}<5$, baixos teores de cálcio e magnésio e altos teores de alumínio trocável (Marimon Júnior \& Haridasan 2005).

Foram selecionadas 12 espécies pertencentes a sete famílias botânicas: Clusiaceae (Kielmeyera rubriflora Cambess.), Dilleniaceae (Davilla elliptica A. St.-Hil.), Malpighiaceae (Byrsonima coccolobifolia Kunth e Byrsonima pachyphylla Griseb.), Myrtaceae (Eugenia aurata O. Berg., Myrcia lanuginosa O. Berg.), Ochnaceae (Ouratea hexasperma (A. St.-Hil.) Baill., Ouratea spectabilis (Mart. ex Engl.) Engl.), Proteaceae (Roupala montana Aubl.) e Vochysiaceae (Qualea grandiflora Mart., Qualea multiflora Mart., Qualea parviflora Mart.) (Tabela 1). A escolha das espécies foi realizada em função do número de indivíduos adultos na área, do 
Tabela 1. Espécies lenhosas estudadas em um cerrado típico no Parque Municipal do Bacaba, Nova Xavantina, Mato Grosso, e seus respectivos grupos fenológicos, período e síndromes de dispersão. $\mathrm{PRE}=$ Precoce; $\mathrm{RET}=$ Retardada; $\mathrm{TAR}=$ Tardia; Zoo = Zoocórica; Ane $=$ Anenocórica; $\mathrm{N}=\mathrm{Número}$ de indivíduos .

Table 1. Woody species investigated in a typical cerrado in the Bacaba Municipal Park, Nova Xavantina, Mato Grosso, and their respective phonological group, period and dispersal syndrome. PRE = Precocious flowering; RET = delayed flowering; TAR = late flowering; Zoo = Zoochorous; Ane = Anemochorous; $\mathrm{N}=$ Number of individuals.

\begin{tabular}{|c|c|c|c|c|c|}
\hline Grupos fenológicos vegetativos ${ }^{1}$ /Espécies & Família & $\mathbf{N}$ & Floração ${ }^{2}$ & $\begin{array}{l}\text { Período de } \\
\text { dispersão }\end{array}$ & $\begin{array}{c}\text { Síndrome de } \\
\text { dispersão }^{3}\end{array}$ \\
\hline \multicolumn{6}{|l|}{ Sempre verdes com crescimento contínuo (SVC) } \\
\hline Myrcia lanuginosa $\mathrm{O}$. Berg. & Myrtaceae & 13 & PRE & Chuva & Zoo \\
\hline Ouratea hexasperma (A. St.-Hil.) Baill. & Ochnaceae & 11 & PRE & Chuva & Zoo \\
\hline Ouratea spectabilis (Mart. ex Engl.) Engl. & Ochnaceae & 12 & PRE & Chuva & Zoo \\
\hline Roupala montana Aubl. & Proteaceae & 12 & TAR & Seca/chuva & Ane \\
\hline \multicolumn{6}{|l|}{ Sempre verdes com crescimento sazonal (SVS) } \\
\hline Byrsonima pachyphylla Kunth & Malpighiaceae & 12 & TAR & Chuva & Zoo \\
\hline \multicolumn{6}{|l|}{ Brevidecíduas (BDC) } \\
\hline Davilla elliptica A. St.-Hil. & Dilleniaceae & 12 & TAR & Seca/chuva & Zoo \\
\hline Eugenia aurata $\mathrm{O}$. Berg. & Myrtaceae & 6 & RET & Seca & Zoo \\
\hline \multicolumn{6}{|l|}{ Decíduas (DEC) } \\
\hline Byrsonima coccolobifolia Kunth & Malpighiaceae & 12 & RET & Chuva & Zoo \\
\hline Kielmeyera rubriflora Cambess. & Clusiaceae & 12 & TAR & Seca & Ane \\
\hline Qualea grandiflora Mart. & Vochysiaceae & 12 & RET & Seca & Ane \\
\hline Qualea multiflora Mart. & Vochysiaceae & 12 & RET & Seca/chuva & Ane \\
\hline Qualea parviflora Mart. & Vochysiaceae & 11 & RET & Seca & Ane \\
\hline
\end{tabular}

Com base em: ' ${ }^{2}$ enza \& Klink (2006); ${ }^{2}$ Oliveira (2008); ${ }^{3}$ van der Pijl (1982).

grau de deciduidade foliar ou da sua importância em termos Índice de Valor de Importância (IVI). Juntas essas 12 espécies representam $41 \%$ do IVI total da comunidade (Marimon Junior \& Haridasan 2005). De cada espécie, foram marcados de 11 a 13 indivíduos adultos e com vestígios de estágio reprodutivo anterior, exceto para Eugenia aurata que teve somente seis indivíduos marcados (Tabela 1). Isso ocorreu pois esses foram os únicos indivíduos de E. aurata encontrados na área que não foi atingida pelo fogo, que ocorreu no Parque pouco antes do início do presente estudo. Tendo em vista que o fogo poderia ter efeitos sobre os eventos fenológicos dos indivíduos amostrados, as coletas foram realizadas somente nas áreas não atingidas pelo fogo.

As observações fenológicas foram realizadas em intervalos quinzenais, no período compreendido entre 19 de setembro de 2008 e 03 de outubro de 2009. Para cada espécie, foi estimada a cobertura total da folhagem na copa da planta e registrada a ocorrência de brotamento (fenologia vegetativa) e presença de flores e frutos imaturos e maduros (fenologia reprodutiva). Os eventos vegetativos e reprodutivos foram estimados visualmente, com auxílio de binóculo quando necessário. Por brotamento considerouse o desenvolvimento inicial das gemas. Foi estimada também a proporção relativa de folhas jovens (folhas recém formadas, com lâmina já expandida e coloração diferenciada das folhas adultas), folhas adultas (folhas com características morfológicas e estruturais completas) e folhas senescentes (folhas adultas com alteração da coloração típica da espécie) na copa dos indivíduos. Para quantificação das fenofases descritas acima, foi adotado o método proposto por Fournier (1974), que consiste numa escala intervalar semi-quantitativa composta por cinco categorias ( 0 a 4), sendo: 0 = ausência da fenofase; 1 = intensidade entre 1 e $25 \%$; $2=$ intensidade entre 26 e $50 \% ; 3=$ intensidade entre 51 e $75 \%$ e $4=$ intensidade entre 76 e $100 \%$.
Para todas as fenofases de cada espécie calculou-se o índice de Fournier (IF), dado em valores de porcentagem e calculado por meio da Equação 1:

$$
\text { IF }=\sum \text { ei/im. } 100
$$

onde: ei = estimativa da intensidade da fenofase na planta; im = valor alcançado pela população se todos os indivíduos apresentarem intensidade máxima da fenofase

As fenofases estimadas por Fournier foram representadas graficamente para cada espécie separadamente. A partir dos dados individuais as espécies foram classificadas em grupos fenológicos vegetativos sugeridos por Sarmiento \& Monasterio (1983), modificados por Lenza \& Klink (2006) e Oliveira (2008) e que determinam, respectivamente, o grau de deciduidade foliar e o momento de ocorrência da floração em relação ao período chuvoso. Adicionalmente, os dados de cada planta na população foram considerados separadamente para determinação do tempo individual médio de senescência. Em relação aos eventos fenológicos vegetativos as espécies lenhosas podem se comportar como: 1) Sempre verde com crescimento contínuo (SVC) (sem deciduidade evidente e produção de folhas por períodos prolongados); 2) sempre verde com crescimento sazonal (SVS) (sem deciduidade completa, mas com substituição da folhagem na transição entre o período seco e chuvoso), 3) brevidecíduas (BDC) (com deciduidade completa dos indivíduos na estação seca por um período de tempo inferior a duas semanas); e 4) decíduas (DEC) (com deciduidade completa dos indivíduos na estação seca por um período de tempo superior a duas semanas).

Em relação aos eventos fenológicos reprodutivos, seguindo Oliveira (2008), as espécies foram classificadas em quatro grupos fenológicos, dependendo do período de ocorrência da floração em relação à estação chuvosa: 1) Precoce (floração no início da estação chuvosa), 2) retardada (floração durante a estação chuvosa), 3) tardia (floração durante a estação seca) e 4) oportunista (floração ocasional 
ou fortuita). As espécies foram ainda classificadas quanto à síndrome de dispersão do diásporo, de acordo com van der Pijl (1982) em: 1) zoocóricas; 2) anemocóricas; 3) autocóricas.

Para verificar possíveis relações entre a cobertura de folhagem na copa, brotamento, floração e maturação dos frutos e as variáveis ambientais (precipitação total quinzenal, médias quinzenais das temperaturas mínimas, máximas e de Déficit de Pressão de Vapor DPV) foi utilizada a análise de correlação de Spearman $\left(\mathrm{r}_{\mathrm{s}}\right)$ (Zar 1999). O DPV foi calculado a partir das médias quinzenais de umidade relativa e da temperatura média do ar de acordo com Rundel \& Jarrel (1989). Para maior refinamento da análise de correlação foi calculada a média quinzenal para as variáveis ambientais, se ajustando assim aos dados fenológicos que também tiveram observações quinzenais.

Os dados climáticos do período de estudo, e dos últimos dez anos para precipitação foram fornecidos pela Estação Meteorológica da UNEMAT em Nova Xavantina (INMET 83319-MT), distante cerca de $800 \mathrm{~m}$ da área de estudo e na mesma altitude $(320 \mathrm{~m})$. Para caracterização completa dos dois períodos secos que podem ter interferido nos eventos fenológicos optou-se por apresentar os dados climáticos de maio de 2008 a setembro de 2009 (Figura 1). Durante o período de estudo (outubro de 2008 a setembro de 2009), a precipitação anual foi $1.333 \mathrm{~mm}$, semelhante à média dos últimos dez anos (1.400 mm). A média de precipitação para o período seco (de maio a setembro) entre os anos de 1999 e 2008 foi $41 \pm 33 \mathrm{~mm}$. No entanto, no período seco de 2008 houve baixa precipitação $(17 \mathrm{~mm})$ e longo período sem chuvas (maio a agosto), enquanto que no mesmo período no ano de 2009 a precipitação foi elevada (126,6 mm) e com ausência de precipitação apenas em julho (Figura 1).

As temperaturas médias mensais durante o período de estudo variaram entre $28{ }^{\circ} \mathrm{C}$ (outubro) e $22{ }^{\circ} \mathrm{C}$ (junho), com média anual de $25{ }^{\circ} \mathrm{C}$. As médias mensais das temperaturas mínimas variaram entre $23{ }^{\circ} \mathrm{C}$ (novembro) e $15^{\circ} \mathrm{C}$ (julho), com média anual de $20^{\circ} \mathrm{C}$, enquanto as médias mensais das máximas variaram entre $38{ }^{\circ} \mathrm{C}$ (setembro) e $31^{\circ} \mathrm{C}$ (dezembro), resultando em uma média anual de $34{ }^{\circ} \mathrm{C}$ (Figura 1).

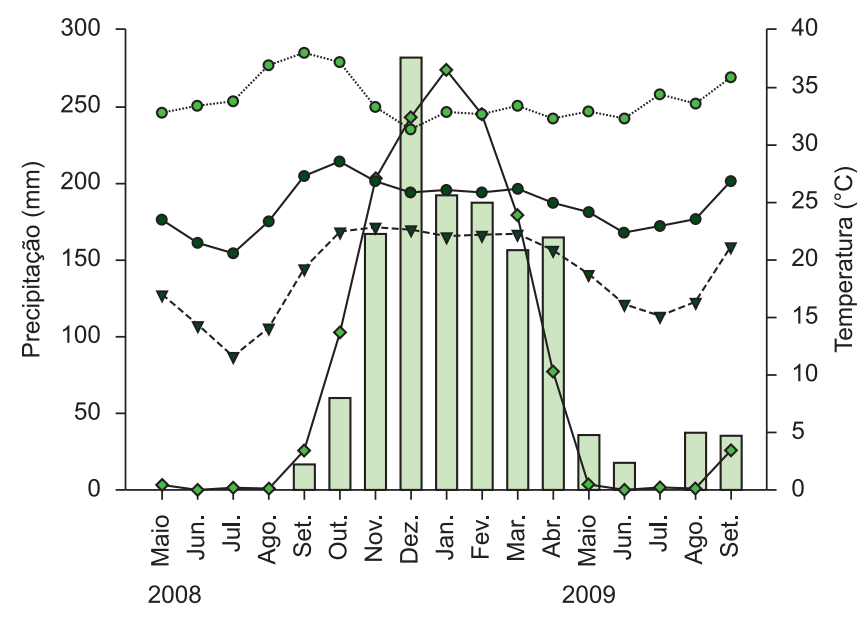

$\square$ Precipitação total mensal
$\diamond$ Média mensal de precipitação para os últimos 10 anos
- Média mensal das temperaturas máximas
- Média mensal das temperaturas do ar
- Média mensal das temperaturas mínimas

Figura 1. Climatograma do Parque Municipal do Bacaba, Nova Xavantina, Mato Grosso, entre maio de 2008 e setembro de 2009.

Figure 1. Climatogram for the Bacaba Municipal Park, Nova Xavantina, Mato Grosso, from May 2008 to September 2009.

\section{Resultados}

\section{Comportamento fenológico vegetativo das populações}

Espécies sempre verdes com crescimento contínuo (SVC) - As quatro espécies desse grupo (Myrcia lanuginosa, Ouratea hexasperma, O. spectabilis e Roupala montana) apresentaram discreta redução na cobertura de folhagem na copa (cuja cobertura sempre foi superior a 50\%) e aumento em folhas senescentes (geralmente inferior a $20 \%$ da cobertura) em curto período na transição entre a estação seca e a chuvosa, sem que houvesse a troca completa da folhagem dos indivíduos nesse período. Ao contrário, o brotamento ocorreu por tempo prolongado com produção de folhas jovens tanto na estação seca quanto na chuvosa. Dessa forma, houve renovação quase contínua da folhagem, com elevada porcentagem de folhas adultas nas copas dos indivíduos ao longo do ano com troca intensa, mas apenas parcial da folhagem, entre os períodos seco e chuvoso (Figura 2). Nas espécies Myrcia lanuginosa, Ouratea hexasperma e O. spectabilis a troca parcial da folhagem foi mais evidente e intensa no final do período seco do ano de 2008 (mês de setembro) em relação ao mesmo período do ano 2009.

Espécie sempre verde com crescimento sazonal (SVS) - Esse comportamento foi apresentado apenas por Byrsonima pachyphylla, e foi caracterizado pela queda de folhas e brotamento no final do período seco e início do período chuvoso (agosto a novembro) (Figura 3a, b). A cobertura de copa alcançou os menores valores no final do período seco, no mês de setembro. Em outubro houve maior brotamento e a proporção de folhas jovens na copa apresentou os maiores índices (48\%). Assim, no final da estação seca, a queda foliar quase concomitante com a formação de folhas novas na copa, levou a troca completa da folhagem dos indivíduos. No restante do ano, a espécie se manteve com $100 \%$ de cobertura de copa composta predominantemente por folhas adultas (Figura 3b). A redução da cobertura da copa em B. pachyphylla foi mais intensa no fim do período seco de 2008 (47\% em setembro de 2008) em relação ao período seco de 2009 (73\% em setembro de 2009).

Espécies brevidecíduas (BDC) - A cobertura de folhagem na copa para as duas espécies brevidecíduas (Davilla elliptica e Eugenia aurata), foi composta principalmente por folhas adultas durante todo o período chuvoso (novembro a abril) e na maior parte do período seco (maio a agosto). A troca completa da folhagem, caracterizada por um pico de senescência foliar antecedendo um pico de brotamento e produção de folhas novas, ocorreu entre os meses de setembro e outubro, ou seja, no final da estação seca (Figura 4). Nesses dois meses, as duas populações apresentaram baixa cobertura de copa (geralmente inferiores a 50\%) (Figura 4) e todos os indivíduos permaneceram sem folhas em algum momento, por um período de aproximadamente duas semanas (baseado nos dados de cada indivíduo separadamente). Tanto em Davilla elliptica quanto em Eugenia aurata a redução de folhagem na copa foi mais intensa no fim do período seco de 2008 ( 8 e $21 \%$ respectivamente) do que no período seco de 2009 (29 e $58 \%$ respectivamente). Em D. elliptica foi observada a produção de folhas, embora menos intensa, também ao longo do período chuvoso.

Espécies decíduas (DEC) - O comportamento fenológico vegetativo das cinco espécies decíduas (Byrsonima coccolobifolia, Kielmeyera rubriflora, Qualea grandiflora, Q. multiflora e $Q$. parviflora) foi semelhante àquele apresentado pelas espécies brevidecíduas, ou seja, a senescência, brotamento e renovação da folhagem ocorreram no fim da estação seca e início das chuvas, enquanto que, ao longo do período chuvoso, a copa dos indivíduos foi composta predominantemente por folhas adultas (Figura 5). No entanto, os indivíduos das espécies decíduas permaneceram 

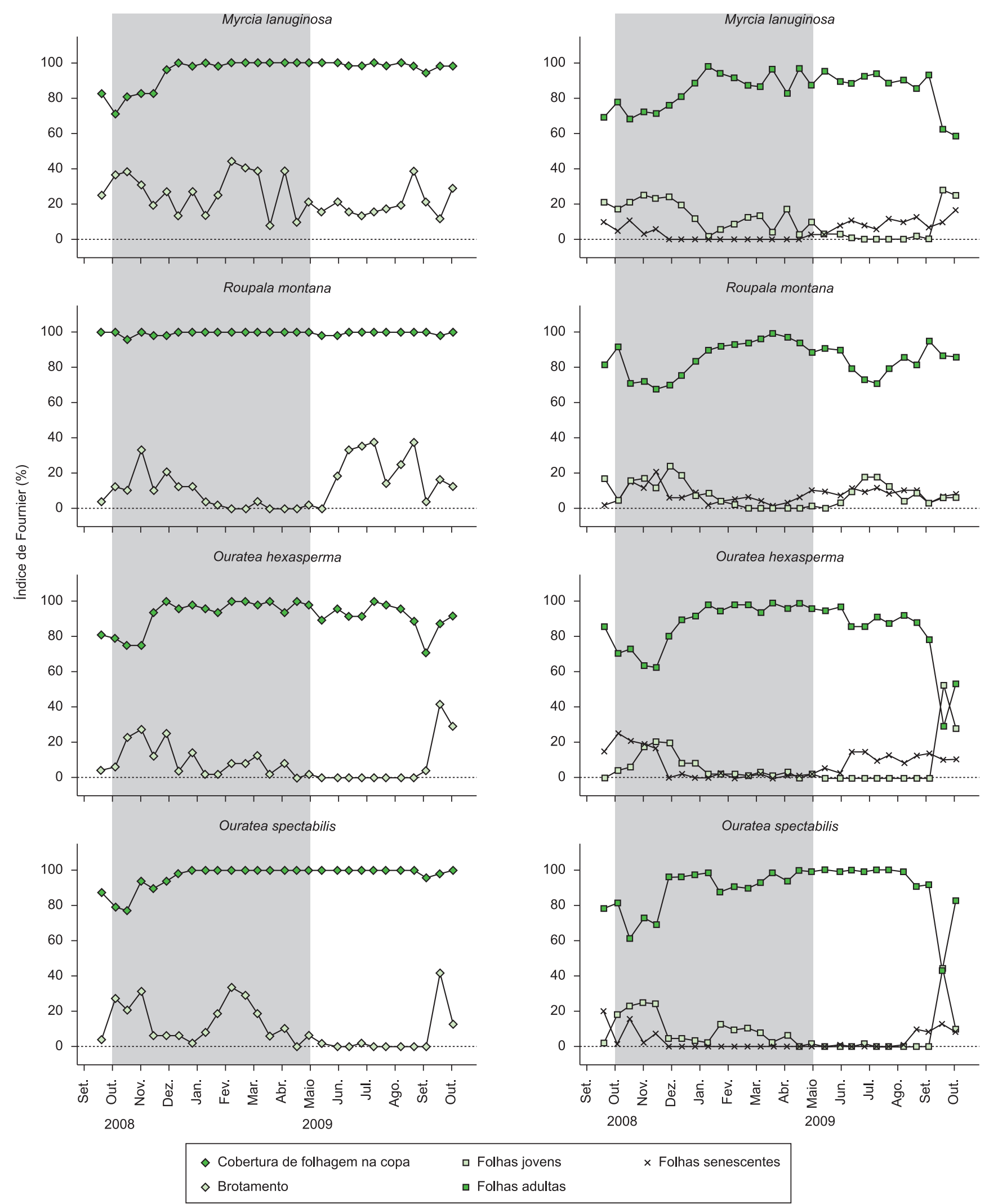

Figura 2. Índice de Fournier (\%) dos eventos fenológicos vegetativos das espécies sempre verdes com crescimento contínuo em um cerrado típico, de setembro de 2008 a outubro de 2009 no Parque Municipal do Bacaba, Nova Xavantina, MT. Área cinza indica período chuvoso.

Figure 2. Fournier index (\%) for the vegetative phenological events of evergreen species with continuous growth in a typical cerrado, from September 2008 to October 2009 in the Bacaba Municipal Park, Nova Xavantina, MT. The gray area indicates the rainy period. 


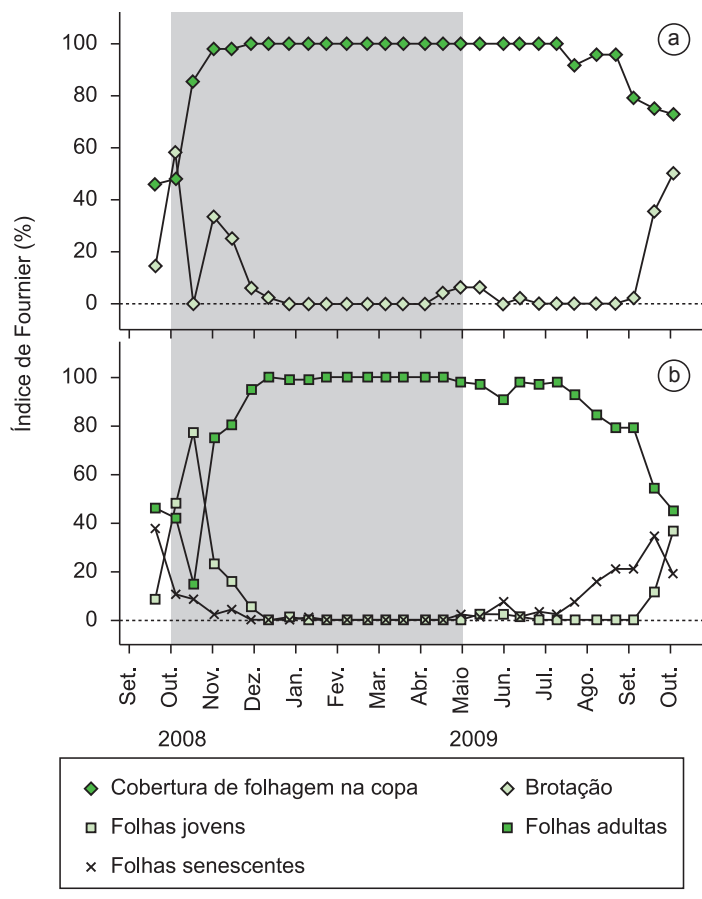

Figura 3. Índice de Fournier (\%) dos eventos fenológicos vegetativos da espécie sempre verde com crescimento sazonal (Byrsonima pachyphylla) no Parque Municipal do Bacaba em Nova Xavantina, MT, uma área de cerrado típico, de setembro de 2008 a outubro de 2009. Área cinza indica período chuvoso.

Figure 3. Fournier index (\%) for the vegetative phenological events for the evergreen species with seasonal growth (Byrsonima pachyphylla) in the Bacaba Municipal Park, Nova Xavantina, MT, a typical cerrado, from September 2008 to October 2009. The gray area indicates the rainy period.

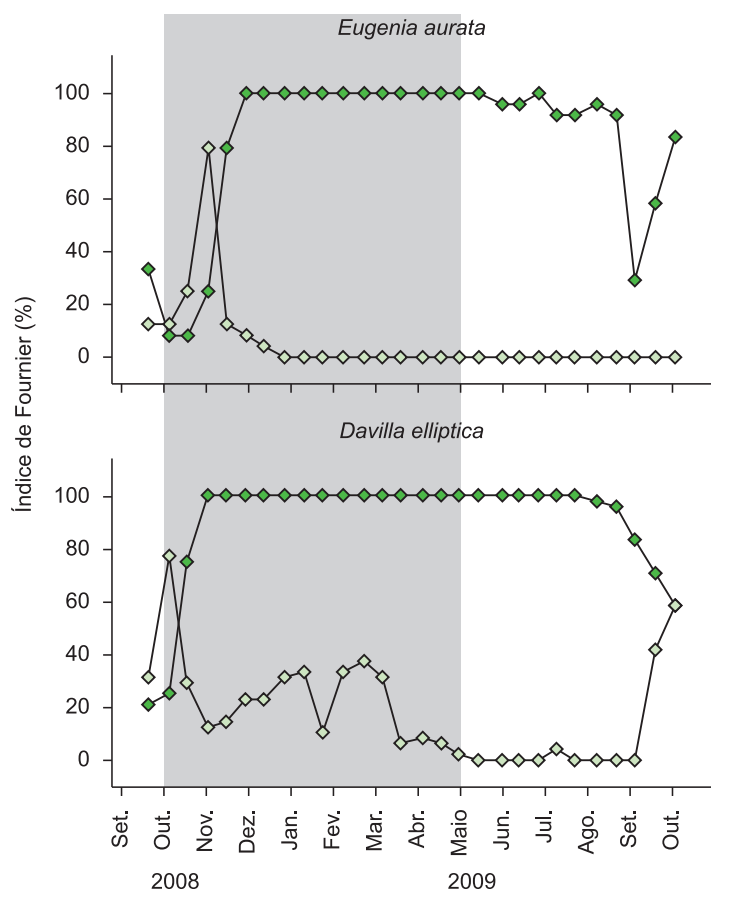

$\begin{array}{lll}\diamond \text { Cobertura de folhagem na copa } & \square \text { Folhas jovens } & \times \text { Folhas senescentes } \\ \diamond \text { Brotamento } & \square \text { Folhas adultas }\end{array}$

Figura 4. Índice de Fournier (\%) dos eventos fenológicos vegetativos de duas espécies brevidecíduas em um cerrado típico, entre 2008 e 2009 no Parque Municipal do Bacaba, Nova Xavantina, MT. Área cinza indica período chuvoso.

Figure 4. Fournier index (\%) for the vegetative phenological events of two brevideciduous species in a typical cerrado, from September 2008 to October 2009 , in the Bacaba Municipal Park, Nova Xavantina, MT. The gray area indicates the rainy period. 

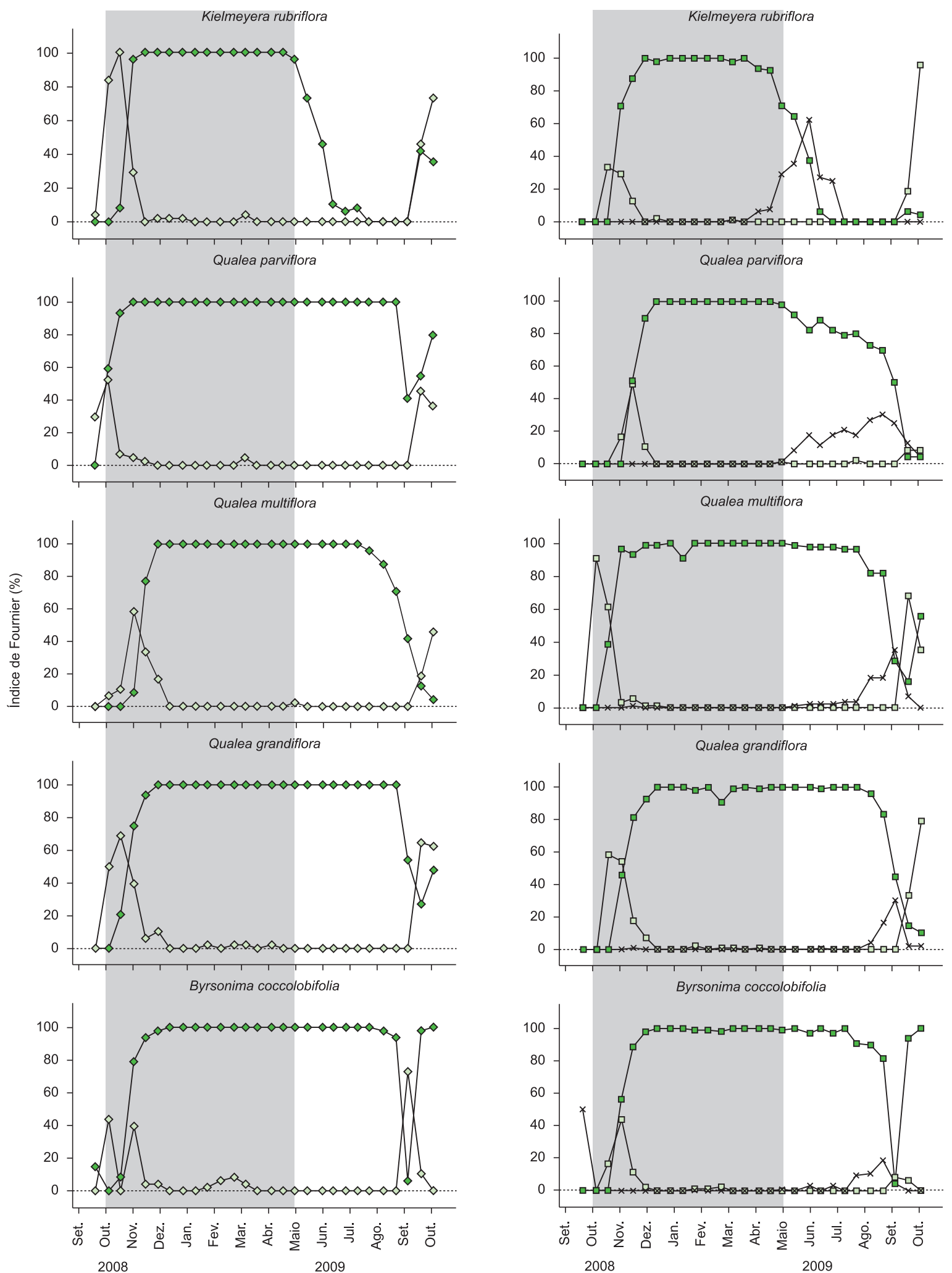

$\begin{array}{|ll|}\diamond \text { Cobertura de folhagem na copa } & \square \text { Folhas jovens } \\ \diamond \text { Brotamento } & \square \text { Folhas adultas }\end{array}$

Figura 5. Índice de Fournier (\%) dos eventos fenológicos vegetativos das espécies decíduas em um cerrado típico, de setembro de 2008 a outubro de 2009 no Parque Municipal do Bacaba, Nova Xavantina, MT. Área cinza indica período chuvoso.

Figure 5. Fournier index (\%) for the vegetative phenological events of deciduous species in a typical cerrado, from September 2008 to October 2009 , in the Bacaba Municipal Park, Nova Xavantina, MT. The gray area indicates the rainy period. 

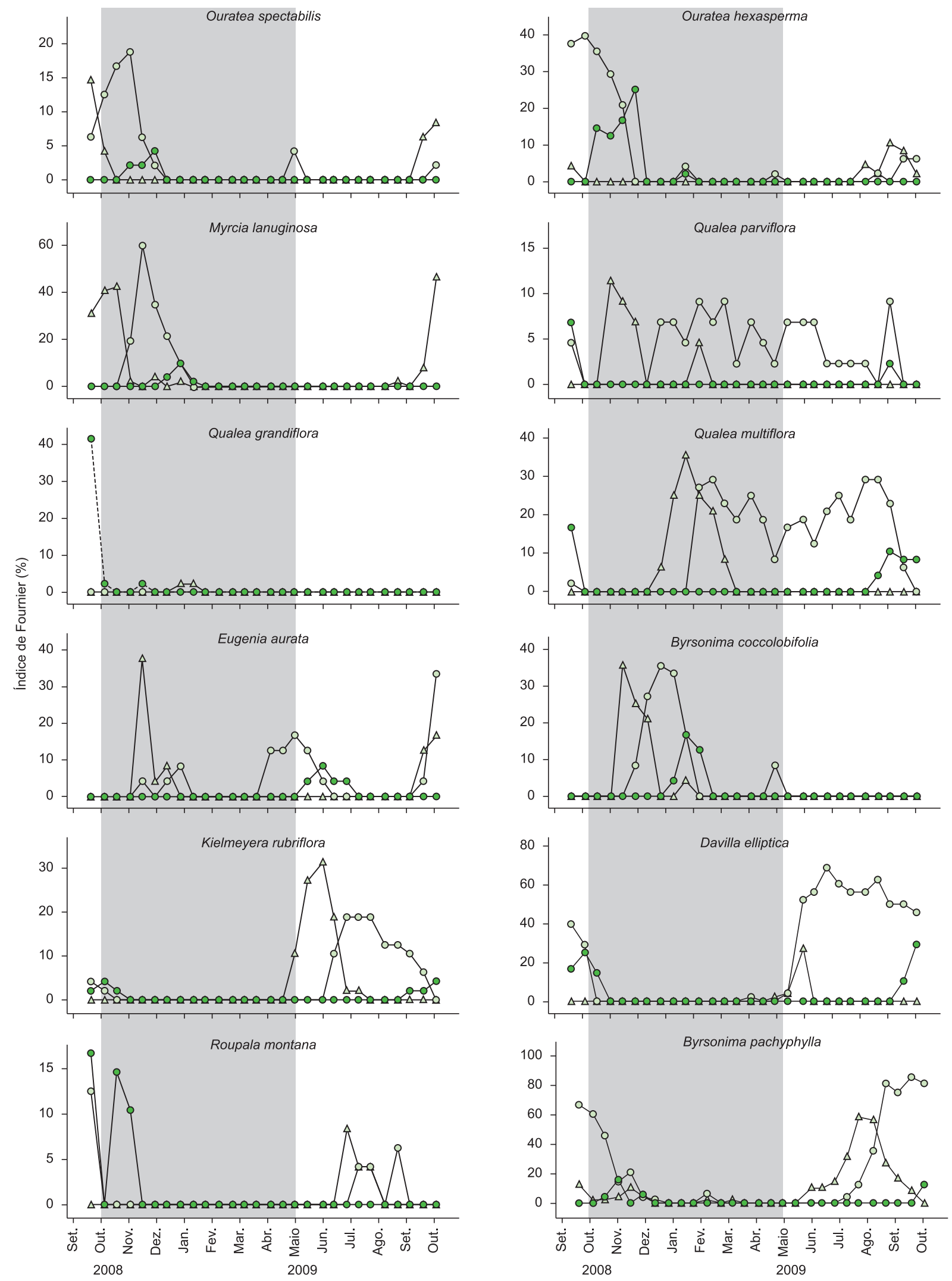

$\Delta$ Flor $\quad$ o Fruto imaturo $\quad$ Fruto maduro

Figura 6. Índice de Fournier (\%) dos eventos fenológicos reprodutivos de 12 espécies lenhosas em um cerrado típico, de setembro de 2008 a outubro de 2009 no Parque Municipal do Bacaba, Nova Xavantina, MT. Área cinza indica período chuvoso.

Figure 6. Fournier index (\%) for the reproductive phenological events of 12 woody species in a typical cerrado, from September 2008 to October 2009 , in the Bacaba Municipal Park, Nova Xavantina, MT. The gray area indicates the rainy period. 
parviflora e Q. multiflora, enquanto em Byrsonima coccolobifolia o desenvolvimento durou pouco mais de um mês (Figura 6). No entanto, independente do tempo decorrido entre o pico de floração e o de maturação dos frutos, a dispersão das sementes foi concentrada na transição entre as estações seca e chuvosa, com nove das 12 espécies com pico de maturação dos frutos entre os meses de setembro e novembro (Figura 6).

\section{Relação entre fenofases e variáveis ambientais}

A cobertura de copa de 11 das 12 espécies estudadas, independente do comportamento fenológico vegetativo, apresentou correlação negativa e significativa com a temperatura máxima e o DPV, sempre com maiores valores de correlação observados para o DPV. Apenas Roupala montana, espécie estritamente sempre-verde, não apresentou relação entre a cobertura de copa e a temperatura máxima e o DPV. Foi observada correlação entre precipitação e cobertura de copa para quatro espécies e entre temperatura mínima e cobertura de copa para duas espécies e essas correlações ocorreram para espécies pertencentes a distintos grupos fenológicos vegetativos (Tabela 2).

A temperatura mínima foi a variável climática mais relacionada ao brotamento das espécies estudadas (correlação positiva com nove espécies), ainda que cinco espécies apresentassem correlação entre o brotamento e o DPV, três com a temperatura máxima e duas com a precipitação. Em geral, as correlações ocorreram independentemente do comportamento fenológico das espécies, ou seja, uma mesma variável climática se correlacionou de maneira semelhante com espécies com comportamentos fenológicos distintos (Tabela 2).

A temperatura mínima também apresentou correlação significativa com a floração para a maioria das espécies estudadas (cinco positivas e quatro negativas), embora tenha sido observada correlação dessa fenofase com o DPV (cinco positivas e uma negativa), com a temperatura máxima (quatro positivas e duas negativas) e com a precipitação (uma positiva e três negativas) (Tabela 2).
As cinco espécies anemocóricas (Tabela 1) e uma zoocórica com fruto deiscente (Davilla elliptica) apresentaram relação positiva e significativa entre a maturação dos frutos e a temperatura máxima e o DPV, indicando que a dispersão dos diásporos destas espécies ocorre quando há um aumento na temperatura máxima e na demanda evaporativa do ar. As correlações entre o período de maturação e as variáveis de precipitação e temperatura mínima foram menos evidentes para as 12 espécies estudadas.

Analisando conjuntamente as 192 correlações possíveis entre as quatro variáveis ambientais e as quatro fenofases das 12 espécies estudadas, nota-se que a precipitação é a variável climática com menor número de correlações significativas. Observa-se ainda que o brotamento das espécies foi consistentemente relacionado com elevações na temperatura mínima e que aumentos na cobertura de copa estão fortemente associados com temperaturas máximas mais baixas e com um menor déficit de pressão de vapor.

\section{Discussão}

A abscisão foliar e o brotamento ocorrendo predominantemente no período seco sugerem forte sazonalidade dessas fenofases nas espécies estudadas. Esta dinâmica foliar sazonal é comum em espécies lenhosas de fitofisionomias savânicas do bioma Cerrado (Mantovani \& Martins 1988, Oliveira \& Gibbs 2000, Lenza \& Klink 2006, Oliveira 2008), determina o caráter semidecidual sazonal da vegetação lenhosa (Lenza \& Klink 2006) e sugere que a restrição hídrica é um dos fatores determinantes dos eventos fenológicos vegetativos das espécies lenhosas. Tomados em conjunto, os estudos sobre o comportamento fenológico vegetativo de espécies lenhosas de formações savânicas do Cerrado indicam que o comportamento de troca completa (decíduo e brevidecíduo) ou parcial da folhagem (sempre verde com crescimento sazonal) é a estratégia mais amplamente adotada pelas espécies para lidar com as restrições ambientais (Franco et al. 2005, Lenza \& Klink 2006, Pirani et al. 2009).

Tabela 2. Matriz de correlação de Spearman $\left(\mathrm{r}_{\mathrm{s}}\right.$ ) entre a Precipitação total quinzenal (PR), médias quinzenais das Temperaturas Mínimas (TMI), médias quinzenais Temperaturas Máximas (TMX), Déficit de Pressão de Vapor (DPV) e a cobertura de folhagem na copa, brotamento, floração e frutos maduros para 12 espécies lenhosas estudadas no Parque Municipal do Bacaba, Nova Xavantina, MT.

Table 2. Spearman's correlation matrix ( $r_{s}$ ) between total fortnightly precipitation (PR), average fortnightly minimum temperature (TMI), average fortnightly maximum temperature (TMX), vapour pressure deficit (DPV) and the leaf canopy cover, sprouting, flowering and mature fruit for 12 woody species studied in the Bacaba Municipal Park, Nova Xavantina, MT.

\begin{tabular}{|c|c|c|c|c|c|c|c|c|c|c|c|c|c|c|c|c|}
\hline \multirow{2}{*}{ Copa } & \multicolumn{4}{|c|}{ Copa } & \multicolumn{4}{|c|}{ Brotamento } & \multicolumn{4}{|c|}{ Floração } & \multicolumn{4}{|c|}{ Fruto maduro } \\
\hline & $\mathbf{P R}$ & TMI & TMX & DPV & PR & TMI & TMX & DPV & PR & TMI & TMX & DPV & PR & TMI & TMX & DPV \\
\hline \multicolumn{17}{|c|}{ Sempre verdes com crescimento contínuo (SVC) } \\
\hline M. lanuginosa & 0,16 & $-0,33$ & $-0,50 *$ & $-0,69 *$ & 0,26 & 0,30 & 0,11 & $-0,02$ & $-0,11$ & $0,44^{*}$ & $0,55^{*}$ & $0,64 *$ & $0,39 *$ & 0,32 & $-0,43^{*}$ & $-0,36$ \\
\hline O. hexasperma & 0,26 & 0,01 & $-0,41 *$ & $-0,66^{*}$ & $0,42 *$ & $0,82 *$ & 0,16 & $-0,01$ & $-0,50 *$ & $-0,53^{*}$ & $0,54^{*}$ & $0,61^{*}$ & 0,25 & $0,57 *$ & 0,15 & 0,23 \\
\hline O. spectabilis & 0,10 & $-0,56^{*}$ & $-0,52 *$ & $-0,59^{*}$ & 0,37 & $0,64 *$ & 0,09 & $-0,17$ & $-0,36$ & $-0,08$ & $0,72^{*}$ & $0,76^{*}$ & 0,24 & $0,55^{*}$ & 0,05 & 0,14 \\
\hline R. montana & 0,14 & $-0,19$ & $-0,16$ & $-0,28$ & $-0,45^{*}$ & $-0,24$ & 0,17 & $0,54 *$ & $-0,57 *$ & $-0,67^{*}$ & $-0,18$ & 0,12 & $-0,24$ & 0,22 & $0,40^{*}$ & $0,43^{*}$ \\
\hline \multicolumn{17}{|c|}{ Sempre verdes com crescimento sazonal (SVS) } \\
\hline B. pachyphylla & $0,40 *$ & $-0,03$ & $-0,80 *$ & $-0,84 *$ & $-0,24$ & $0,38^{*}$ & $0,38 *$ & $0,47 *$ & $-0,77 *$ & $-0,68 *$ & 0,32 & $0,60 *$ & 0,04 & $0,48^{*}$ & 0,19 & 0,26 \\
\hline \multicolumn{17}{|c|}{ Brevidecíduas (BDC) } \\
\hline D. elliptica & $0,38^{*}$ & 0,02 & $-0,74 *$ & $-0,77^{*}$ & 0,33 & $0,68^{*}$ & 0,11 & $-0,14$ & $-0,31$ & $-0,41^{*}$ & $-0,38 *$ & $-0,21$ & $-0,40^{*}$ & 0,15 & $0,61 *$ & $0,61 *$ \\
\hline E. aurata & $0,49 *$ & 0,02 & $-0,73 *$ & $-0,86^{*}$ & $-0,21$ & $0,42 *$ & $0,43 *$ & $0,58 *$ & 0,15 & $0,49 *$ & 0,15 & 0,24 & $-0,35$ & $-0,48 *$ & $-0,40^{*}$ & $-0,06$ \\
\hline \multicolumn{17}{|l|}{ Decíduas (DEC) } \\
\hline K. rubriflora & $0,75^{*}$ & $0,56^{*}$ & $-0,61 *$ & $-0,81^{*}$ & $-0,08$ & $0,56^{*}$ & 0,38 & 0,35 & $-0,18$ & $0,44^{*}$ & $0,41^{*}$ & $0,56^{*}$ & $-0,35$ & 0,13 & $0,68^{*}$ & $0,67 *$ \\
\hline Q. grandiflora & 0,26 & $-0,33$ & $-0,66^{*}$ & $-0,69^{*}$ & $-0,13$ & 0,19 & 0,29 & 0,29 & 0,37 & 0,35 & $-0,23$ & $-0,16$ & $-0,14$ & 0,22 & $0,40 *$ & $0,42 *$ \\
\hline Q. multiflora & 0,34 & $-0,15$ & $-0,77 *$ & $-0,82 *$ & $-0,07$ & $0,53^{*}$ & 0,35 & $0,40 *$ & $0,53 *$ & 0,31 & $-0,42 *$ & $-0,62 *$ & $-0,27$ & $-0,16$ & $0,51 *$ & $0,54 *$ \\
\hline Q. parviflora & 0,36 & $-0,09$ & $-0,67 *$ & $-0,67^{*}$ & $-0,24$ & $0,39 *$ & $0,59 *$ & $0,53 *$ & 0,07 & $0,49 *$ & 0,19 & 0,18 & $-0,19$ & $-0,08$ & $0,41^{*}$ & $0,41 *$ \\
\hline B. coccolobifolia & 0,18 & $-0,32$ & $-0,71 *$ & $-0,79 *$ & 0,14 & $0,58^{*}$ & $0,42 *$ & 0,27 & 0,22 & $0,62 *$ & 0,11 & 0,20 & 0,16 & 0,05 & 0,02 & $-0,17$ \\
\hline
\end{tabular}

*Significativo em nível de $5 \%$. 
Em geral, espécies lenhosas de formações savânicas do Cerrado possuem adaptações morfológicas e ecofisiológicas que limitam a perda e maximizam o uso de água em resposta à limitação hídrica sazonal, como forte controle estomático (Franco 2002, Naves-Barbiero et al. 2000, Bucci et al. 2005), folhas pilosas e esclerófilas (Oliveira et al. 2003) e raízes profundas, capazes de absorver e armazenar água (Warming 1973, Oliveira \& Silva 1993, Oliveira et al. 2005, Jackson et al. 1999). Entre essas adaptações, a perda ou substituição completa da folhagem no período hídrico desfavorável também atua como um mecanismo na economia e eficiência do uso de água pelas plantas. Assim, a redução na disponibilidade de água na estação seca parece funcionar como fator de indução à queda de folhas, como discutido por Pedroni et al. (2002).

Oito das 12 populações avaliadas no presente estudo apresentaram evidências da indução climática e do ajuste fenológico das plantas à condição de redução da disponibilidade de água, uma vez que a abscisão foliar dessas espécies foi mais intensa em setembro de 2008, que apresentou período seco mais severo do que no mesmo período em 2009. O fato da cobertura foliar da copa de 11 das 12 espécies estudadas ter apresentado relação negativa e significativa com o DPV confirma esta idéia, indicando que o aumento da demanda evaporativa está relacionado a perda da folhagem da copa das plantas, independentemente do comportamento fenológico apresentado pela espécie. Apesar do papel chave da precipitação como fonte de água para as plantas, o presente estudo sugere que a abscisão foliar parece responder mais diretamente à demanda evaporativa do ar. Segundo Lenza (2005), a disponibilidade de água no solo também exerce influência sobre os eventos fenológicos vegetativos de espécies lenhosas de cerrado sentido restrito. Assim, os eventos fenológicos vegetativos das espécies parecem depender do balanço entre água disponível no solo e a demanda de água na atmosfera e aguardam estudos específicos para sua confirmação.

Algumas espécies podem apresentar o mesmo comportamento de abscisão foliar em diferentes regiões, como em Qualea parviflora, que se comportou como decídua tanto neste estudo como nos estudos de Figueiredo (2008), no nordeste do Maranhão e de Marquis et al. (2001) e Franco et al. (2005), ambos no Distrito Federal. Outras podem apresentar variações como Roupala montana e Davilla elliptica, que se comportaram, respectivamente, como SVC e BDC no presente estudo e como SVS e DEC, respectivamente, no estudo de Lenza \& Klink (2006). Este fato indica que a produção e queda foliar em espécies lenhosas do cerrado sentido restrito podem apresentar plasticidade fenotípica, permitindo que as espécies apresentem ampla distribuição espacial no bioma e ainda ocupem ecossistemas com distintos substratos e níveis de restrição hídrica.

A temperatura mínima parece ser a variável climática mais fortemente relacionada à indução do brotamento e da floração no conjunto das espécies estudadas. A emissão de folhas jovens, ocorrendo principalmente na transição entre as estações de seca e chuva e a correlação significativa desta fenofase principalmente com a temperatura mínima sugerem tais fatores como possíveis indutores do brotamento nas espécies estudadas. O aumento da temperatura mínima parece indicar a iminência do período chuvoso, estimulando o brotamento para recomposição da copa e maximização do processo de fotossíntese durante o período chuvoso. Folhas recém formadas são mais suscetíveis à lixiviação de nutrientes pela água das chuvas (Sarmiento et al. 1985) e sua produção justamente na transição entre seca e chuva, período no qual as precipitações ainda são menos intensas, pode ser uma estratégia para reduzir perdas de nutrientes por lixiviação dos tecidos foliares (Lenza \& Klink 2006).

Apesar de haver espécies em floração ao longo do ano, um maior número de espécies floresceu no início e durante a estação chuvosa, como também constatado em cerrados de São Paulo (Mantovani \&
Martins, 1988, Tannus et al. 2006), Distrito Federal (Lenza \& Klink 2006) e Goiás (Batalha \& Martins 2004). Segundo Mantovani \& Martins (1988), este padrão pode ser visto como uma adaptação às condições de aumento na precipitação, temperatura média mensal e fotoperíodo. Em espécies como Qualea grandiflora, Q. parviflora, Q. multiflora e Byrsonima coccolobifolia, apenas após a recomposição da folhagem na copa ao final da estação seca é que ocorre a floração, fato que restringe a ocorrência desse evento à estação chuvosa.

Quatro espécies do presente estudo foram estudadas também por Lenza \& Klink (2006) no Distrito Federal e três delas, Ouratea hexasperma, Qualea grandiflora e Roupala montana, apresentaram o mesmo padrão de floração (precoce, retardada e tardia, respectivamente) registrado no presente estudo. Entretanto, Davilla elliptica que se comportou como tardia no presente estudo apresentou floração retardada no estudo de Lenza \& Klink (2006), indicando que a precipitação pode não ser determinante no ajuste temporal da floração desta espécie. Além do mais, das variáveis ambientais analisadas no presente estudo, a floração desta espécie só apresentou relação com a temperatura mínima e parece haver um ótimo para a sua floração, visto que no presente estudo as primeiras flores foram observadas em maio, quando a média da temperatura mínima mensal foi de $18{ }^{\circ} \mathrm{C}$ e no estudo de Lenza e Klink (2006) a espécie começou a florir em janeiro quando a média mensal de temperatura mínima também estava em torno de 17 a $18{ }^{\circ} \mathrm{C}$.

$\mathrm{O}$ padrão de floração anual e unimodal, com picos rápidos e sincrônicos, apresentado pela maioria das espécies do presente estudo, também foi verificado por Lenza \& Klink (2006), constituindo estratégia que parece ser comum entre as espécies polinizadas por insetos, favorecendo a atração de polinizadores e facilitando o fluxo de pólen e a polinização cruzada (Augspurger 1981, Marquis 1988).

Como observado também no presente estudo, as espécies anemocóricas de comunidades lenhosas de Cerrado, de forma geral, dispersam frutos durante o período seco, enquanto a dispersão de espécies zoocóricas ocorre predominantemente durante o período chuvoso (Mantovani \& Martins 1988, Batalha \& Mantovani 2000, Lenza \& Klink 2006, Oliveira 2008). Uma exceção a este padrão foi observada para Eugenia aurata que mesmo sendo zoocórica dispersou frutos durante a estação seca (maio a julho de 2009). Entretanto, o referido episódio de frutificação parece ser um evento esporádico, principalmente devido à baixa intensidade, e ao fato de dois meses após (setembro de 2009), se iniciar um novo evento reprodutivo com maior intensidade. Esta explicação está de acordo com Oliveira \& Paula (2001) que apresentam o período de frutificação de Eugenia aurata como sendo de setembro a abril, uma estação predominantemente chuvosa no bioma Cerrado.

A dispersão de frutos anemocóricos na estação seca, como verificado no presente estudo, é favorecida pelo dessecamento do pericarpo provocado principalmente pela baixa umidade do ar e o aumento na velocidade dos ventos (Batalha \& Mantovani 2000, Oliveira 2008). O fato da dispersão de todas as espécies anemocóricas apresentarem relação positiva e significativa com o DPV confirma esta idéia. Nesse sentido, a redução da cobertura de folhas na vegetação nesse período, também facilita a abertura dos frutos e a dispersão das sementes (Lenza \& Klink 2006). Por outro lado, a dispersão dos frutos zoocóricos durante o período chuvoso é favorecida pela maior atividade dos dispersores, e pela alta umidade que garante uma atratividade dos frutos por períodos mais prolongados melhorando as chances de dispersão (Mantovani \& Martins 1988, Batalha \& Mantovani 2000, Oliveira 2008).

Diferente do comportamento de floração, com espécies florescendo ao longo de todo o ano, a maturação dos frutos, considerando as 12 espécies conjuntamente, esteve concentrada nos três meses de transição entre a estação seca e a chuvosa (setembro a 
novembro). Esse fato confirma a proposta de Oliveira (2008) de que há um ajustamento das demais fenofases para garantir que a dispersão, principalmente das sementes que não apresentam dormência, ocorra em um período favorável à sua germinação, que coincide com o início do período chuvoso. Assim, frutos secos e anemocóricos do Cerrado possuem vantagens para dispersão na seca, enquanto frutos carnosos e zoocóricos se beneficiam com a maturação nas chuvas (Batalha \& Mantovani 2000, Oliveira 2008), maximizando a dispersão das sementes. Por outro lado a ligação temporal e funcional entre as distintas fenofases parece ser o fator determinante para o sucesso de germinação e estabelecimento dos novos indivíduos na população.

Este estudo fornece evidências do ajuste fenológico vegetativo das espécies lenhosas de cerrado sentido restrito às variações na quantidade de água disponível para as plantas, uma vez que oito das doze espécies aqui estudadas apresentaram deciduidade foliar mais intensa no ano de 2008, cuja estação seca foi mais rigorosa. A suposta plasticidade fenotípica dos eventos vegetativos, apresentada por essas espécies, fornece a oportunidade de condução de novos estudos testando o valor adaptativo da flexibilidade fenológica na ocupação de ambientes com distintas limitações hídricas e consequentemente na distribuição geográfica dessas espécies no bioma Cerrado.

\section{Referências Bibliográficas}

AUGSPURGER, C.K. 1981. Reproductive synchrony of a tropical plant: experimental effects of pollinators and seed predators on Hybanthus prunifolius (Violaceae). Ecology 62(3):775-788.

BATALHA, M.A. \& MANTOVANI, W. 2000. Reproductive phenology patterns of cerrado plant species at the Pé-de-Gigante Reserve (Santa Rita do Passa Quatro, SP, Brazil): a comparison between the herbaceous and woody flora. Rev. Bras. Biol. 60(1):129-145.

BATALHA, M.A. \& MARTINS, F.R. 2004. Reproductive phenology of the cerrado plant community in Emas National Park (central Brazil). Aust. J. Bot. 52:149-161.

BRIDGEWATER, S., RATTER, J.A. \& RIBEIRO, J.F. 2004. Biogeographic patterns, b-diversity and dominance in the cerrado biome of Brazil. Biodiv. Cons. 13(12):2295-2318.

BUCCI, S.J., GOLDSTEIN, G., MEINZER, F.C., FRANCO, A.C., CAMPANELLO, P. \& SCHOLZ, F.G. 2005. Mechanisms contributing to seasonal homeostasis of minimum leaf water potential and predawn disequilibrium between soil and plant water potential in Neotropical savanna trees. Trees 19(3):296-304.

COUTINHO, L.M. 1990. Fire in the ecology of the Brazilian Cerrado. In Fire in the tropical Biota: Ecological processes and global challenges. (J.G. Goldammer, ed.). Spring-Verlag, New York. p.82-105.

DELITTI, W.B.C. 1995. Estudos de ciclagem de nutrientes: instrumentos para a análise funcional de ecossistemas terrestres. In Oecologia Brasiliensis. v.1. (F.A. Esteves, ed.). Estrutura, funcionamento e manejo de ecossistemas brasileiros. Ed. IB/UFRJ. Rio de Janeiro. p.470-485.

EITEN, G. 1972. The cerrado vegetation of Brazil. Bot. Rev. 38:201-341.

FELFILI, J.M., SILVA JUNIOR, M.C., DIAS, B.J. \& REZENDE, A.V. 1999 Estudo fenológico de Stryphnodendron adstringens (Mart.) Coville no cerrado sensu stricto da Fazenda Água Limpa, no Distrito Federal, Brasil. Rev. Bras. Bot. 22(1):83-90.

FERNANDES-BULHÃO, C. \& FIGUEIREDO P.S. 2002. Fenologia das leguminosas arbóreas em uma área de cerrado marginal no nordeste do Maranhão. Rev. Bras. Bot. 25(3):361-369.

FIGUEIREDO, P.S. 2008. Fenologia e estratégias reprodutivas das espécies arbóreas em uma área marginal de cerrado, na transição para o semi-árido no nordeste do Maranhão, Brasil. Rev. Trópica 2(2):8-21.

FILGUEIRAS, T.S. 2002. Herbaceous plant communities. In The cerrados of Brazil (P.S. Oliveira \& R.J. Marquis, eds.). Columbia University Press, New York, p.121-138.

FOURNIER, L.A. 1974. Un método cuantitativo para la medición de características fenológicas en árboles. Turrialba 24(4):422-423.
FRANCO, A.C. 2002. Ecophysiology of woody plants. In The cerrados of Brazil (P.S. Oliveira \& R.J. Marquis, eds.). Columbia University Press, New York, p.178-197.

FRANCO, A.C., BUSTAMANTE, M., CALDAS, L.S., GOLDSTEIN, G., MEINZER, F.C., KOZOVITS, A.R., RUNDEL, P., CORADIN, V.T.R. 2005. Leaf functional traits of Neotropical savanna trees in relation to seasonal water deficit. Trees 19:326-335.

FROST, P.G.H \& ROBERTSON, F. 1987. The ecological effects of fire in Savannas. In Ecology and management of the world Savanas. (J.C. Tothill \& J.J. Mott, eds.). Australian Academy Science, Camberra. p.93-139.

HARIDASAN, M. 2000. Nutrição mineral de plantas nativas do cerrado. Rev. Bras. Fisiol. Veg. 12:54-64.

JACKSON, P.C., MEINZER, F.C., BUSTAMANTE, M., GOLDSTEIN, G., FRANCO, A.C., RUNDEL, P.W., CALDAS L.S., IGLER, E. \& CAUSIN, F. 1999. Partitioning of soil water among tree species in a Brazilian Cerrado. Tree Physiol. 19(11):717-724.

LENZA, E. \& KLINK, C.A. 2006 Comportamento fenológico de espécies lenhosas em um cerrado sentido restrito de Brasília, DF. Rev. Bras. Bot. 29(4):627-638.

LENZA, E. 2005. Fenologia, demografia foliar e características foliares de espécies lenhosas em um cerrado sentido restrito no Distrito Federal e suas relações com as condições climáticas. Tese de doutorado, Universidade de Brasília, Brasília.

LIETH, H. 1974. Introduction to phenology and the modeling of seasonality. Phenology and seasonality modeling. In Ecological Studies 8. (H. Lieth, ed.). Springer-Verlag, Berlin, p.3-19.

MANTOVANI, W. \& MARTINS, F.R. 1988. Variações fenológicas das espécies do cerrado da Reserva Biológica de Moji-Guaçu, Estado de São Paulo. Rev. Bras. Bot. 11:101-112.

MARIMON Jr., B.H. \& HARIDASAN, M. 2005. Comparação da vegetação arbórea e características edáficas de um cerradão e um cerrado stricto sensu em áreas adjacentes sobre solo distrófico no leste de Mato Grosso, Brasil. Acta Bot. Bras. 19(4):913-926.

MARQUIS, R.J. 1988. Phenological variation in the Neotropical understory shrub Piper arieianum: causes and consequences. Ecology 69(5):1552-1565.

MARQUIS, R.J., DINIZ, I.R. \& MORAIS, H.C. 2001. Patterns and correlates of interspecific variation in foliar insect herbivory and pathogen attack in Brazilian cerradão. J. Trop. Ecol. 17(1):127-148.

MARQUIS, R.J., MORAIS, H.C. \& DINIZ, I.R. 2002. Interactions among Cerrado plants and their herbivores: unique or typical? In The cerrados of Brazil (P.S. Oliveira \& R.J. Marquis, eds.). Columbia University Press, New York, p.306-328.

MENDONÇA, R.C., FELFILI, J.M., WALTER, B.M.T., SILVA Jr., M.C., REZENDE, A.V., FILGUEIRAS, T.S., NOGUEIRA, P.E. \& FAGG, C.W 2008. Flora vascular do bioma Cerrado. In Cerrado: ecologia e flora vol. 2 (S.M. Sano, S.P. Almeida \& J.F. Ribeiro, eds.). Embrapa Informação Tecnológica, Brasília, p.222-1279.

MIRANDA, H.S., BUSTAMANTE, M. \& MIRANDA, A.C. 2002. The fire factor. In The cerrados of Brazil (P.S. Oliveira \& R.J. Marquis, eds.). Columbia University Press, New York, p.51-68.

MIRANDA, H.S., SATO, M.N., ANDRADE, S.M.A., HARIDASAN, M. \& MORAIS, H.C. 2004. Queimadas de Cerrado: caracterização e impactos. In Cerrado ecologia e caracterização (Aguiar, L.M.S. \& Camargo, A.J.A., eds.). EMBRAPA Cerrados, Planaltina, DF, p.69-123.

MUNHOZ, C.R.B. \& FELFILI, J.M. 2007. Reproductive phenology of an herbaceous-subshrub layer of a Savannah (Campo Sujo) in the Cerrado Biosphere Reserve I. Brazil. Braz. J. Biol. 67(2):299-307.

NAVES-BARBIERO, C.C., FRANCO, A.C., BUCCI, S.J. \& GOLDSTEIN, G. 2000. Fluxo de seiva e condutância estomática de duas espécies lenhosas sempre-verdes no campo sujo e cerradão. Rev. Bras. Fisiol. Veg. 12(2):119-134.

OLIVEIRA, A.F.M., MEIRELLES, S.T. \& SALATINO, A. 2003. Epicuticular waxes from caatinga and cerrado species and their efficiency against water loss. An. Acad. Bras. Cienc. 75(4):431-439. 
OLIVEIRA, P.E. \& GIBBS, P.E. 2000. Reproductive biology of woody plants in a cerrado community of the central Brazil. Flora 195:311-329.

OLIVEIRA, P.E. \& PAULA, F.R. 2001. Fenologia e biologia reprodutiva de plantas de matas de galeria. In Cerrado caracterização e recuperação de matas de galeria. (J.F. Ribeiro, C.E.L. Fonseca \& J.C. Sousa-Silva, eds.). EMBRAPA-CEPAC, Planaltina, p.303-332.

OLIVEIRA, P.E. \& SILVA, J.C.S. 1993. Reproductive Biology of two species of Kielmeyera (Guttiferae) in the Cerrados of Central Brazil. J. Trop. Ecol. 9(1):67-79.

OLIVEIRA, P.E. 2008. Fenologia e biologia reprodutiva das espécies de Cerrado. In Cerrado: ambiente e flora. (S. M. Sano \& S.P. Almeida, eds.). EMBRAPA - Cerrados, Planaltina, p.169-188.

OLIVEIRA, R.S., BEZERRA, L., DAVIDSON, E.A., PINTO, F., KLINK, C.A., NEPSTAD, D.C. \& MOREIRA, A. 2005. Deep root function in soil water dynamics in cerrado savannas of central Brazil. Funct. Ecol. 19(4):574-581.

PEDRONI, F., SANCHEZ, M. \& SANTOS, F.A.M. 2002. Fenologia da copaíba (Copaifera langsdorffi Desf. - Leguminosae, Caesalpinioideae) em uma floresta semidecídua no sudeste do Brasil. Rev. Bras. Bot. 25(2):183-194.

PIRANI, F.R., SANCHEZ, M. \& PEDRONI, F. 2009. Fenologia de uma comunidade arbórea em cerrado sentido restrito, Barra do Garças, MT. Acta Bot. Bras. 23(4):1096-1109.

RADAMBRASIL. 1981. Levantamento de recursos naturais. Rio de Janeiro, Ministério das Minas e Energia. SD-22/Goiás.

RATTER, J.A., BRIDGEWATER, S. \& RIBEIRO, J.F. 2003. Analysis of the floristic composition of the Brazilian cerrado vegetation III: Comparison of the woody vegetation of 376 areas. Edinb. J. Bot. 60(1):57-109.

REATTO, A., CORREIA, J.R., SPERA, S.T. \& MARTINS, E.S. 2008. Solos do Bioma Cerrado: aspectos pedológicos. In Cerrado: ecologia e flora (S.M. Sano, S.P. Almeida \& J.F. Ribeiro, eds.). Embrapa Cerrados, Brasília, p.107-149.

RIBEIRO, J.F. \& WALTER, B.M.T. 2008. As principais fitofisionomias do bioma Cerrado. In Cerrado: ecologia e flora (S.M. Sano, S.P. Almeida \& J.F. Ribeiro, eds.). Embrapa Informação Tecnológica, Brasília, p.151-212.
RUNDEL, P.W. \& JARREL, W.M. 1989. Water in the environment. In Plant physiological ecology: field methods and instrumentation (R.W. Pearcy, J. Ehleringer, H.A. Mooney \& P.W. Rundel, eds.). Chapman \& Hall, London.

SARMIENTO, G. \& MONASTERIO, M. 1983. Life forms and phenology. In Ecosystems of the World: tropical savannas (F. Bouliere, ed.). Elsevier, Amsterdan, p.79-108.

SARMIENTO, G., GOLDSTEIN, G. \& MEINZER, F. 1985.Adaptative strategies of woody species in neotropical savannas. Biol. Rev. 60:315-355

SILVA, F.A.M., ASSAD, E.D. \& EVANGELISTA, B.A. 2008. Caracterização climática do Bioma Cerrado. In Cerrado: ecologia e flora (S.M. Sano, S.P. Almeida \& J.F. Ribeiro, eds.). Embrapa Cerrados, Brasília, p.61-88.

SILVA, J.F., FARIÑAS, M.R., FELFILI, J.M. \& KLINK, C.A. 2006. Spatial heterogeneity, land use and conservation in the cerrado region of Brazil. J. Biogeog. 33(3):536-548.

TALORA, D.C. \& MORELLATO, P.C. 2000. Fenologia de espécies arbóreas em floresta de planície litorânea do sudeste do Brasil. Rev. Bras. Bot. 23(1):13-26.

TANNUS, J.L.S., ASSIS, M.A. \& MORELLATO, L.P.C. 2006. Fenologia reprodutiva em campo sujo e campo úmido numa área de cerrado no sudeste do Brasil, Itirapina - SP. Biota Neotropica 6(3): http://www. biotaneotropica.org.br/v6n3/pt/abstract?article+bn02806032006.

van der PIJL, L. 1982. Principles of dispersal in higher plants. Springer Verlag, New York.

WARMING, E. 1973. Lagoa Santa; a vegetação de cerrados brasileiros. In Lagoa Santa. (E. Warming \& M.G. Ferri, eds.). EDUSP, São Paulo, ITATIAIA, Belo Horizonte, p.1-284.

ZAR, J.H. 1999. Biostatistical Analysis. $4^{\text {th }}$ ed. Prentice Hall, New Jersey.

Recebido em 29/12/2009

Versão reformulada recebida em 22/08/2010

Publicado em 06/09/2010 